fibrosis: Prevailing and evolving hypotheses about its pathogenesis and implications for therapy. Ann Intern Med 2001;134:136-51

2. Navaratnam V, Fleming KM, West J, et al. The rising incidence of idiopathic pulmonary fibrosis in the U.K. Thorax 2011;66:462-7.

3. Demedts M, Behr J, Buhl R, et al; IFIGENIA study Group. High-dose acetylcysteine in idiopathic pulmonary fibrosis. N Engl J Med 2005;353:2229-42.
4. Bradley B, Branley HM, Egan JJ, et al. Interstitial lung disease guideline: the British Thoracic Society in collaboration with the Thoracic Society of Australia and New Zealand and the Irish Thoracic Society. Thorax 2008;63(Suppl 5):v1-58.

5. Raghu G, Collard HR, Egan JJ, et al. An Official ATS/ERS/ JRS/ALAT Statement: idiopathic pulmonary fibrosis: evidence-based guidelines for diagnosis and management. Am J Respir Crit Care Med 2011;183:788-824.
6. http://clinicaltrials.gov/ct2/show/NCT00650091 (accessed 8 Nov 2011).

7. http://www.pulmonaryfibrosis.org/node/679 (accessed 8 Nov 2011)

8. http://www.nhlbi.nih.gov/new/pantherQA.htm (accessed 8 Nov 2011).

9. Nathan SD, du Bois RM. Idiopathic pulmonary fibrosis trials: recommendations for the jury. Eur Respir $J$ 2011:38:1002-4.

\title{
The asbestos disease epidemic: here today, here tomorrow
}

\section{Paul Cullinan, ${ }^{1}$ Neil Pearce ${ }^{2}$}

In what may be the best ever use of a Wellcome grant, Geoffrey Tweedale, in his fascinating history of the multinational asbestos company Turner \& Newall, ${ }^{1}$ reminds us that asbestos was once known as the 'magic mineral'. Indeed, in many ways, it is the ideal construction material: tough, durable, light in weight, fire-resistant and very cheap. Unfortunately, asbestos is also, as every respiratory physician knows, highly toxic when inhaled. Total bans on its use are in place in 52 countries including those of the European Union, Australia, Japan and South Africa ${ }^{2}$; and its use is tightly restricted in the USA, New Zealand and Canada-the last, ironically, among the world's largest exporters of the material.

Readers from these countries may be surprised to learn that elsewhere the production, sale and use of asbestos continue to flourish and even increase. In 1994, one of us (NP) edited a book ${ }^{3}$ on occupational cancer in developing countries for the International Agency for Research on Cancer and reported that global asbestos production and use had not declined; rather, the problem was simply being moved from Western countries to emergent economies. Unhappily, the situation has not improved in the intervening 17 years. In India, for example, the use of asbestos has doubled in the last decade to about 300000 tonnes a year by an industry that now employs

\footnotetext{
${ }^{1}$ Department of Occupational and Environmental Medicine, National Heart and Lung Institute, London, UK; ${ }^{2}$ Epidemiology and Public Health, London School of Hygiene and Tropical Medicine, London, UK

Correspondence to Dr Paul Cullinan, Department of Occupational and Environmental Medicine, National Heart and Lung Institute, 1b Manresa Road, London SW3 6LR, UK; p.cullinan@imperial.ac.uk
}

an estimated 100000 workers. ${ }^{4}$ Other major users include China, Brazil, Russia, Ukraine, Kazakhstan and Indonesia. In these parts of the world, where occupational exposures may be difficult to control and enforce, the great majority of asbestos is mixed with cement in the manufacture of sheets for roofing or pipes for sanitation and irrigation in contrast to the uses once common in Europe and North America.

There is a further contrast in the nature of the asbestos used in contemporary manufacturing. Almost all of the estimated 2 million tonnes mined each year is now chrysotile ('white' asbestos) with very little extraction of crocidolite ('blue'), amosite ('brown') or other amphibole (straight-fibre) types. In part, this is a result of the disputed belief that different types of asbestos have different toxicities. Certainly, all are both fibrogenic and carcinogenic but it is often argued that chrysotile is less so than the amphibolesat least with regard to mesothelioma-and that the exposures required to induce asbestosis and malignancies are considerably higher when chrysotile alone is being handled. It is on this basis, with the message that "chrysotile is safe if it is used safely', that the powerful mining, industrial and governmental interests (particularly in Canada and Russia) justify and fight for the continuing sale and use of the mineral across the developing world. On the other hand, there are a number of studies $^{5-8}$ which indicate that chrysotile exposure does increase the rate of lung cancer, with risks comparable to those shown with amphiboles, although the risks of mesothelioma remain uncertain and are likely to be lower than those from amphiboles. ${ }^{9}$ A corollary of this is that the ratio of lung cancer cases to mesothelioma cases is likely to be higher for chrysotile than for amphiboles; thus, estimates of asbestos-related lung cancer, which are based on reported mesothelioma cases, require a larger 'multiplying factor' for chrysotile than for amphiboles.

The Chongqing asbestos plant in China opened in 1939 and expanded rapidly between 1958 and 1996 using up to 6000 tonnes of raw asbestos annually to manufacture textiles, asbestos cement products, rubber products and friction and heat-resistant materials. Only chrysotile asbestos extracted from mines in Sichuan has been used in the plant; a limited analysis of ore samples from these mines in 2000 was unable to detect any contamination by amphibole (tremolite) asbestos. ${ }^{10}$ Thus a study of the employees in the plant should provide important insights into the toxicology of essentially pure chrysotile.

In this issue of Thorax, researchers from Hong Kong and Sichuan report the results of their 37-year retrospective cohort study of employees from the Chongqing asbestos plant. ${ }^{11}$ A reference group of workers in an electronics factory in the same city was established and followed for the same period. The findings are striking: a more than threefold increase in the risk of death from lung cancer (and also non-malignant respiratory disease) was observed among the asbestos workers after statistical control for smoking, in the asbestos cohort, with clear evidence of an exposure-response relationship in both non-smokers and smokers. There were two deaths from mesothelioma in the asbestos cohort-presumably the same two reported in an earlier 25-year follow-up study of the same cohort. ${ }^{10}$

The study has some significant limitations. The authors have been unable to verify the claim that the factory has only ever used tremolite-free chrysotile; and it is possible that the employees in the asbestos factory had had previous asbestos exposure elsewhere or that there were alternative, unidentified carcinogens in the study workplace, although these would have had to have been highly potent. 
While follow-up in the asbestos cohort was virtually complete, a quarter of the electronics workers could not be traced.

Nonetheless, we think this publication is important for at least three reasons. First, the setting is that of a rapidly industrialising nation, one of many where asbestos use is both common and increasing. Almost all of the asbestos literature in publication concerns the experiences of workforces in Europe, North America or other more established economies. Vital lessons have been learnt from these publications, but we urgently need to move beyond the hegemony and understand the risks in those parts of the world where asbestos is now increasingly being used. Second, this is a study of pure or near-pure chrysotile and provides further evidence against the 'amphibole hypothesis', ${ }^{12}$ which assumes that any carcinogenic risks associated with chrysotile are attributable to natural contamination by tremolite. Third, many journal editors are reluctant to publish material on the risks of asbestos, it being merely 'old news'; most funding agencies have similar reservations. A danger of this collective lack of enthusiasm is that the only remaining sponsors of research and publication become those with a vested commercial interest in upsetting the consensus that all forms of asbestos are carcinogenic. $^{13}$

These are not arcane matters. Recent changes in the global economy have shifted manufacturing and its attendant hazards out of Europe and North America to rapidly developing economies in which millions of workers are routinely exposed to serious risks, an issue that, disgracefully, is omitted from virtually every discussion of 'global public health'. For example, an otherwise excellent paper on non-communicable disease in developing countries, recently published in The Lancet, made no mention of occupational exposures; instead, the emphasis was on lifestyle risks such as tobacco, salt and alcohol overuse and obesity. ${ }^{14}$ The tragedy of this focus on personal (lifestyle) factors is that they are difficult to change, ${ }^{15}$ while occupational risk factors are of major importance and are relatively easier to ameliorate. ${ }^{3}$ Exposure to asbestos, widespread and often poorly controlled, is high on the list of these risks with a projected 10 million deaths estimated from its use. ${ }^{16}$ Regular calls for the extraction, sale and use of asbestos to be banned in every country $^{17}$ and repeated efforts to ban or restrict chrysotile asbestos under the Rotterdam Convention are countered by equally regular rebuttals from the extraordinarily powerful lobbies that have an interest in its continuation. The experience of a Chinese factory reported here serves as a sobering reminder that agencies who claim that asbestos is safe if it is used safely are being disingenuous at best. The asbestos disease epidemic is not over, it has simply moved, and occupational health researchers in all parts of the world have an obligation to continue to study its hazards and to work to prevent it repeating itself.

\section{Competing interests None.}

Provenance and peer review Commissioned; internally peer reviewed.

Published Online First 28 October 2011

Thorax 2012;67:98-99.

doi:10.1136/thoraxjnl-2011-201180

\section{REFERENCES}

1. Tweedale G. Magic Mineral to Killer Dust: Turner \& Newall and the Asbestos Hazard. Oxford: Oxford University Press, 2000.
2. International Ban Asbestos Secretariat. 2011. http:// ibasecretariat.org/index.htm

3. Pearce N, Matos E, Vainio $\mathrm{H}$, et al, eds Occupational Cancer in Developing Countries. Lyon: IARC, 1994

4. The Lancet Global Health Network. 2011. http://www. thelancet.com/journals/lancet/article/PIIS0140-6736 (10)60251-6/fulltext (accessed 19 Oct 2011).

5. Loomis D, Dement JM, Wolf SH, et al. Lung cance mortality and fibre exposures among North Carolina asbestos textile workers. Occup Environ Med 2009;66:535-42.

6. Hein MJ, Stayner LT, Lehman E, et al. Follow-up study of chrysotile textile workers: cohort mortality and exposure-response. Occup Environ Med 2007;64:616-25.

7. Cullen MR. Chrysotile asbestos: enough is enough. Lancet 1998;351:1377-8.

8. Stayner LT, Dankovic DA, Lemen RA. Occupational exposure to chrysotile asbestos and cancer risk: a review of the amphibole hypothesis. Am J Public Health 1996:86:179-86.

9. Berman DW, Crump KS. A meta-analysis of asbestos-related cancer risk that addresses fiber size and mineral type. Crit Rev Toxicol 2008; 38(Suppl 1):49-73.

10. Yano E, Wang ZM, Wang XR, et al. Cancer mortality among workers exposed to amphibole-free chrysotile asbestos. Am J Epidemiol 2001;154 538-43.

11. Wang X, Yano E, Qiu H, et al. A 37-year observation of mortality in Chinese chrysotile asbestos workers. Thorax 2012;67:106-10.

12. Mossman BT, Bignon J, Corn M, et al. Asbestos: scientific developments and implications for public policy. Science 1990;247:294-301.

13. Michaels D, Monforton C. How litigation shapes the scientific literature: asbestos and disease among automobile mechanics. J Law Policy 2007;5:1137-69.

14. Beaglehole R, Bonita R, Horton R, et al; Lancet NCD Action Group; NCD Alliance. Priority actions for the non-communicable disease crisis. Lancet 2011;377:1438-47.

15. Ebrahim S, Smith GD. Exporting failure? Coronary heart disease and stroke in developing countries. Int $J$ Epidemiol 2001;30:201-5.

16. LaDou J. The asbestos cancer epidemic. Environ Health Perspect 2004;112:285-90.

17. LaDou J, Castleman B, Frank A, et al. The case for a global ban on asbestos. Environ Health Perspect 2010;118:897-901. 